MODOLELL, Juan Luis. "El tipo objetivo en los delitos de mera actividad".

Polit. crim. Vol. 11, No 22 (Diciembre 2016), Art. 2, pp. 368-390.

[http://www.politicacriminal.cl/Vol_11/n_22/Vol11N22A2.pdf]

\title{
El tipo objetivo en los delitos de mera actividad
}

\section{Objective type in crimes of mere activity}

\author{
Juan Luis Modolell González \\ Profesor de Derecho Penal (Universidad Alberto Hurtado) \\ jmodolell@uahurtado.cl
}

\section{Resumen}

El tipo objetivo en los delitos de mera actividad no puede consistir únicamente en la realización material del hecho. Para su análisis valorativo debe aplicarse el baremo de la perspectiva ex ante a los tipos de mera actividad. Al respecto, deben analizarse dos aspectos: a) si desde un punto de vista ex ante un observador objetivo contaría con la existencia de los diversos elementos exigidos por el tipo para su configuración; b) si un observador objetivo contaría con la posibilidad de que su conducta es peligrosa o lesiva para el bien jurídico.

Palabras clave: Actividad, imputación, resultado, tipo, lesión.

\begin{abstract}
The objective type in crimes of mere activity cannot solely consist in the material execution of the action. For an evaluative analysis the ex ante perspective scale must be applied to types of mere activity. Thus, two aspects must be analyzed: a) if from a ex ante point of view an objective observer would count the existence of diverse elements required by the type to be configured; b) if an objective observer would depend on the possibility that his conduct is dangerous or damaging of the legal good.
\end{abstract}

Key words: Activity, imputation, result, type, injury.

\section{Planteamiento del problema.}

Con relación a los tipos de resultado material se afirma que este no es imputable cuando la conducta que lo causó no ha creado un riesgo jurídico-penalmente relevante ${ }^{1}$. Dentro de este supuesto de imputación objetiva, se comprende el caso de riesgos poco probables de producir el resultado desde un punto de vista ex ante. Se trata de casos en que el peligro ya

\footnotetext{
${ }^{1}$ ROXIN, Claus, "Reflexiones sobre la problemática de la imputación en el Derecho penal", LUZÓN PEÑA (Trad.) en: DEL MISMO, Problemas básicos del Derecho penal, Madrid: Editorial Reus, 1991, p. 131; EL MISMO, Strafrecht. Allgemeiner Teil (en adelante, AT), München, C.H. Beck, 2006, vol. I, p. 377 -55-; EL MISMO, Derecho Penal. Parte General (en adelante, PG), LUZÓN PEÑA, Diego-Manuel; DÍAZ Y GARCÍA CONLLEDO, Miguel; DE VICENTE REMESAL, Javier (Trads.), Madrid: Civitas, 1997, p. 366 $45-$.
} 
MODOLELL, Juan Luis. "El tipo objetivo en los delitos de mera actividad".

existente no sea incrementado de modo mensurable ${ }^{2}$, supuestos en los cuales existe poca probabilidad de aumentar el peligro desde un punto de vista ex ante (criterio de la adecuación) $)^{3}$. Por lo tanto, para poder imputar un resultado relevante, este debe provenir de una conducta adecuada según el hombre medio situado ex ante, tomando en cuenta los conocimientos especiales del autor. Lo anterior explica la inclusión, en este criterio, de la falta de previsibilidad objetiva del resultado ${ }^{4}$.

Ahora bien, si ello pudiera ser claro en los delitos de resultado material, ¿ocurre igual en los tipos de mera actividad? En estos solo se exige la conducta del autor para su realización, sin necesidad de un hecho (suceso) separado de la misma ${ }^{5}$. En dichos delitos, la conducta constituye el principio y el final de la realización típica, el punto final típico ${ }^{6}$.

Desde mi punto de vista, el tipo objetivo en los delitos de mera actividad no puede consistir únicamente en la realización material del hecho ${ }^{7}$. Lo contrario implica que en los delitos de resultado se exige un análisis valorativo adicional que sobra en los de mera actividad, sin que se justifique este desigual tratamiento. En efecto, así como en los delitos de resultado material no basta la sola causación de este para la configuración típica, tampoco en los delitos de mera actividad es suficiente la realización externa de la conducta para que pueda afirmarse la concurrencia del tipo objetivo. Por lo tanto, para determinar la concurrencia de la tipicidad objetiva en esta última clase de delitos es necesario, igualmente, hacer una valoración, un análisis, equivalente al de los delitos de resultado material.

Incluso, se ha sostenido la necesidad de extender criterios de imputación objetiva a esta clase de delitos. Así, el método de utilizar baremos propios de la imputación objetiva, concretamente la perspectiva ex ante, en el tipo objetivo de los delitos de mera actividad se aprecia en Santiago Mir Puig, para quien así como el resultado causado materialmente por una conducta pueda que no sea imputable a esta, por no ser previsible ex ante que causase el resultado, también en los delitos de mera actividad podría no ser previsible, desde un punto de vista ex ante, que la práctica de unos actos corporales determinados supondría la realización de la conducta previa; y agrega este autor el siguiente ejemplo: "El delito de

\footnotetext{
${ }^{2}$ ROXIN, $A T$, vol. I, cit. nota $\mathrm{n}^{\circ} 1$, p. 377 -55-; $P G$, cit. nota ${ }^{\circ}$ 1, p. $367-45-$

${ }^{3}$ Así, ROXIN, $A T$, vol. I, cit. nota $\mathrm{n}^{\circ} 1$, pp. 377 y ss $-56-; P G$, cit. nota $\mathrm{n}^{\circ} 1$, p. 367 -46-; igualmente, ROXIN, "Reflexiones", cit. nota $\mathrm{n}^{\circ}$ 1, p. 132. Sobre la "causalidad adecuada" como antecedente de la imputación objetiva, ver MODOLELL, Juan Luis, Bases fundamentales de la teoría de la imputación objetiva, Caracas: Livrosca, 2001, pp. 60 y ss. Para la crítica a la teoría de la adecuación, ver JAKOBS, Günther, Strafrecht. AT, Berlin-New York: W de G, 1993, pp. 197 y ss. -33 y ss.-; DEL MISMO, Derecho Penal. PG, CUELLO CONTRERAS, Joaquín; SERRANO GONZÁLEZ DE MURILLO, José (Trads.), Madrid: Marcial Pons, 1995 , pp. 239 y ss. -33 y ss.-

${ }^{4}$ Ver ROXIN, "Reflexiones", cit. nota ${ }^{\circ}$ 1, p. 132.

${ }^{5}$ En este sentido Claus Roxin, quien además agrega que en los delitos de mera actividad la realización del tipo coincide con el último acto de la acción (ROXIN, AT, vol. I, cit. nota n ${ }^{\circ} 1$, p. 330 -102 y 103-; también p. 306 -54; $P G$, cit. nota n 1 , pp. 328 y ss. -102 y 103-; y p. $304-54-)$.

${ }^{6}$ MAURACH, Reinhart; ZIPF, Heinza, Strafrecht. AT, Heidelberg: C.F. Müller, 1992, tomo I, p. 286 -27-; GRAUL, Eva, Abstrakte Gefährdungsdelikte und Präsumtionen im Strafrecht, Berlin: Duncker \& Humblot, 1991, p. 20.

${ }^{7}$ MIR PUIG, Santiago, Derecho Penal. PG, Barcelona: Reppertor, 2015, p. 264 -64-. Sobre la extensión de la imputación a los delitos de mera actividad, ver MODOLELL, Juan Luis, "Consideraciones teóricas sobre la posibilidad de extensión de la imputación objetiva a los delitos de mera actividad", en: BOLAÑOS, Mireya (Comp.), Imputación objetiva y dogmática penal, Mérida: Universidad de Los Andes, 2005, pp. 236 y ss.
} 
allanamiento de morada ajena contra la voluntad de su morador...supongamos que atendidas las circunstancias nadie hubiera podido suponer que la morada en la que se entra es ajena o que el morador se opone a tal entrada" ${ }^{\text {. }}$.

\section{Estructura del tipo objetivo en los delitos de mera actividad.}

Desde mi punto de vista, a nivel del tipo objetivo en los delitos de mera actividad, debe realizarse un análisis valorativo-objetivo que permita determinar si la conducta está prohibida. La adecuación al tipo objetivo consiste en afirmar el carácter prohibido general de la conducta realizada, para lo cual debe recurrirse a criterios valorativos similares a los utilizados en la imputación objetiva del resultado material. Al respecto, se pueden extraer conclusiones de Wolfgang Frisch, desarrolladas en torno al dolo, para apuntalar lo anterior. Así, sostiene dicho autor que la conducta prohibida presupuesta en algunos delitos se fundamenta en la "posibilidad de existencia de determinadas circunstancias" exigidas por la figura legal". Dicha "posibilidad" tiene carácter objetivo ${ }^{10}$, determinada mediante el "óptimo juicio según la situación" tomando en cuenta el saber "ontológico" y "nomológico" del autor ${ }^{11}$. Parafraseando un ejemplo de Frisch, en el caso del delito de violación presunta (art. 362, Código penal chileno) el autor debe contar con que la víctima, según un punto de vista ex ante (modo de comportarse, aspecto, etc.), es menor de 14 años $^{12}$. Solo si ex ante concurre dicha posibilidad de existencia, se puede afirmar una conducta típica (prohibida).

Por lo tanto, debe aplicarse el baremo de la perspectiva ex ante a los tipos de mera actividad, para atribuir al autor los elementos objetivos del tipo (descriptivos y normativos). Además, el uso de dicho baremo se extiende a la propia afectación del objeto del bien jurídico protegido. En efecto, primero se atribuyen los mencionados elementos del tipo atendiendo a lo exigible para un hombre medio situado en la posición del autor (mediante una perspectiva ex ante). Adicionalmente, y también desde un punto de vista ex ante, debe determinarse si la conducta tiene la aptitud de afectar valorativamente, no materialmente, el objeto del bien jurídico protegido, o constituir un peligro estadístico para él. Algunas veces la primera forma de aplicación del criterio coincidirá con la segunda, concretamente cuando el tipo penal incorpore en su descripción un elemento que implique la materialización del objeto del bien jurídico, aunque no necesariamente deba ser así. Una vez concluido este doble juicio puede afirmarse que la conducta está prohibida, y que se configura el tipo objetivo.

\footnotetext{
${ }^{8}$ MIR PUIG, $P G$, cit. nota $n^{\text {o }} 7$, p. 264 -62 y 63-. A favor Luzón Peña, para quien en los delitos de mera actividad debe exigirse "la adecuación o idoneidad de la conducta como requisito típico", aunque considera que la falta de adecuación en estos delitos "constituye un fenómeno absolutamente marginal" (LUZÓN PEÑA, Diego-Manuel, Curso de Derecho penal. PG, Madrid: Universitas, 1996, p. 387 -hay reciente edición posterior-).

${ }^{9}$ FRISCH, Wolfgang, Vorsatz und Risiko, Köln-Berlin-Bonn-München: Carl Heymanns, 1983, p. 356.

${ }^{10}$ FRISCH, Vorsatz, cit. nota $n^{\circ} 9$, p. 358 .

${ }^{11}$ FRISCH, Vorsatz, cit. nota n ${ }^{\circ} 9$, p. 359.

${ }^{12} \mathrm{Al}$ respecto, FRISCH, Vorsatz, cit. nota n ${ }^{\circ}$, pp. 371 y ss.
} 
MODOLELL, Juan Luis. "El tipo objetivo en los delitos de mera actividad".

\section{Breve digresión: Función de la norma y estructura del tipo penal.}

Para fundamentar la necesidad del uso de la perspectiva ex ante en el tipo de mera actividad debe hacerse una breve referencia a la estructura general del injusto, la cual se determina según la función que cumple la norma jurídico-penal. Esta persigue lograr un efecto en la conducta de su destinatario, en el sentido de evitar la producción de un determinado estado de cosas o de lograr la producción de alguno. Obviamente, se entiende que destinataria del mandato jurídico-penal, de la amenaza penal, solo puede ser la colectividad a quien se dirige el precepto normativo para influir en ella ("no matar", "no hurtar", "se debe socorrer a una persona en situación de peligro", etc.) $)^{13}$, y no únicamente el juez que aplica la ley penal $^{14}$. La pena establecida por el legislador en el enunciado legal no representa únicamente la definición de la sanción del delito, sino también el medio para influir en el destinatario de la norma. La amenaza penal tiene como propósito intimidar jurídicamente a este (prevención general negativa), así como fomentar el respeto jurídico al valor protegido por ella. Esta visión de la pena lleva a entender el delito mediante una teoría de la norma penal que la defina a través de esas dos funciones: una función de determinación y una de valoración $^{15}$. La primera de ellas se relaciona directamente con el llamado desvalor de conducta, derivado de una visión ex ante del delito ${ }^{16}$, mientras que la segunda función rescata la importancia del bien jurídico, del valor que protege el tipo penal ${ }^{17}$.

${ }^{13}$ En contra de que el contenido de la norma se determine desde la perspectiva de un potencial destinatario, MAÑALICH, Juan Pablo, "Norma e imputación como categorías del hecho punible“, Revista de Estudios de la Justicia (en adelante, REJ) no 12 (2010), pp. 177 y ss.

${ }^{14}$ Para Karl Binding era el Estado el destinatario de la ley penal, solo el Estado es el "posible trasgresor de la ley penal” (BINDING, Karl, Die Normen und ihre Übertretung, Leipzig: Engelmann, 1872, tomo 2, 1, p. 14). Igualmente, es conocida la opinión de Max Ernst Mayer, según la cual la norma jurídica en modo alguno se dirige al ciudadano (MAYER, Max Ernst, Normas jurídicas y normas de cultura, GUZMÁN DALBORA, José Luis (Trad.), Buenos Aires: Hammurabi, 2000, pp. 45 y ss.), sino a los órganos del Estado (pp. 69 y ss.): "...la ley instruye a los funcionarios conforme a qué principios deben administrar justicia” (p. 75). Sobre la discusión científica en relación al destinatario de la norma, ver KRÜGER, Uwe, Der Adressat des Rechtsgesetzes, Berlin: Duncker \& Humblot, 1969, pp. 19 y ss.

15 Hablo de funciones porque en la sociedad moderna, caracterizada por los relaciones anónimas y la necesidad de control social, es esencial definir la norma jurídico-penal en razón del fin que cumple en dicha sociedad.

${ }^{16}$ Contrario a concebir la norma de determinación desde una perspectiva ex ante, MAÑALICH,"Norma e imputación“, cit. nota no 13 , pp. 183 y ss.

${ }^{17}$ En este sentido, ver mi tesis doctoral Bases fundamentales, cit. nota $\mathrm{n}^{\mathrm{o}} 3$, pp. 183 y ss. Sobre la necesidad de una doble perspectiva del concepto de injusto, ver, KRÜMPELMANN, Justus, "Schutzzweck und Schutzreflex der Sorgfaltspflicht“, en: KAUFMANN, Arthur (Ed.), Festschrift für Paul Bockelmann, München: C.H. Beck, 1979, pp. 444 y ss. Similar, LAMPE, Ernst-Joachim, "Unrecht und Schuld, Sühne und Reue“, en: ARZT, Günther; BAUMANN, Jürgen, Festschrift für Jürgen Baumann, Bielefeld: Gieseking, 1992, pp. 24 y ss., aunque dicho autor pareciera hacer énfasis en la función de determinación. Según Luzón Peña, aun siendo fundamental para la efectividad y carácter vinculante de la norma penal la fuerza del imperativo, como este no suele ser pura arbitrariedad, obedece a previas reflexiones y valoraciones que por tanto son su "prius lógico" (Mezger): prohibir una conducta presupone lógicamente desvalorarla, desaprobarla, y en los delitos omisivos, ordenar una conducta implica determinar positivamente a actuar, implica que se valore esa actuación como algo positivo (LUZÓN PEÑA, Curso, cit. nota n 8, pp. 67 y 341. Igualmente, DEL MISMO, "Voz Norma (penal) de determinación y de valoración", en: VV.AA., Enciclopedia Jurídica Básica, Madrid: Civitas, 1995, vol. III, p. 4445; también: DEL MISMO, “Alcance y función del Derecho penal” en: DEL MISMO, Estudios Penales, Barcelona: PPU, 1991, pp. 56 y 50). Desde mi punto de vista, esa valoración previa, ese "prius lógico", también debe formar parte de la norma, o al menos debe ser tomado en cuenta para su interpretación. 
Un sector de la doctrina penal prefiere distinguir entre la norma de conducta (o de determinación) y la llamada "norma de sanción". Se diferencian así aquellas condiciones necesarias para la configuración del injusto (norma de determinación), y aquellas requeridas exclusivamente para la existencia, o graduación, de la sanción penal (norma de sanción) ${ }^{18}$, circunscribiéndose la existencia del injusto al análisis de la primera categoría (norma de determinación). Esta última distinción alude no solo a la relación de la norma con el ciudadano sancionable (destinatario), lo cual configuraría la norma de conducta, sino también se refiere a la relación de la norma con el juez obligado a imponer la sanción ${ }^{19}$. Ello, a su vez, llevaría a distinguir entre aquello que le puede ser exigido al autor, y aquello que el juez debe tomar en cuenta para la aplicación de la sanción ${ }^{20}$.

Es evidente que la distinción entre norma de conducta y norma de sanción apuntala la función determinativa de la norma (norma de conducta) en el injusto, en detrimento de cualquier otra. El solo hecho de concebir una norma de sanción dirigida únicamente al juez, evidencia que esta no cumple papel alguno en la configuración del injusto. Cuestión similar ocurre cuando, al utilizarse la distinción entre la norma de valoración y la norma de determinación, se afirma que la norma solo puede concebirse como determinación, como mandato. Sin embargo, tanto la función determinativa de la norma como su función valorativa son esenciales para la configuración del injusto típico, como explicaré de seguida.

\footnotetext{
${ }^{18}$ Haciendo referencia a esas normas, distingue Wolfgang Frisch entre la conducta típica y la imputación objetiva del resultado: ambas categorías forman parte del supuesto de hecho, sin embargo la primera constituye el centro del injusto y se determina por su contraposición a la llamada norma de conducta (creación de un riesgo desaprobado), mientras que el resultado no formará parte del tipo prohibido sino de lo que denomina "norma de sanción" (al respecto, FRISCH, Wolfgang, Tatbestandsmäßiges Verhalten und Zurechnung des Erfolgs, Heidelberg: C.F. Müller, 1988, passim; para la distinción entre la norma de sanción, el tipo y la norma de conducta, ver FRISCH, Vorsatz, cit. nota ${ }^{\circ}$ 9, p. 348). Lo anterior tiene una relevancia práctica fundamental: dentro del tipo objetivo podrán distinguirse criterios para la imputación objetiva del resultado (para Frisch la imputación objetiva solo se refiere al resultado material, FRISCH, Tatbestandsmäßiges Verhalten, ob. cit., pp. 50 y ss.),y criterios para la determinación del carácter desaprobado (típico) de la conducta. Sobre la diferencia entre conducta típica y la imputación objetiva del resultado, pp. 9 ss., 23 ss., 33 ss. y 50 ss.

${ }^{19}$ Afirma Walter Perron, al referirse a la norma, que esta se desdobla en dos pasos: primero la formación de las normas de conducta, dirigidas al ciudadano como destinatario y a ellos ordena de qué modo comportarse unos con otros; y, segundo, la formación de la normas de sanción, las cuales están dirigidas al juez, funcionario del Estado y por ende aplicador del Derecho, a quien ordena la aplicación de una sanción contra alguien que ha lesionado una determinada norma de conducta. Según Perron, en la práctica son altamente raros los casos de disposición legales penales que sean normas de conductas aisladas; el legislador dicta solo normas de sanción, especialmente en la forma de tipos penales, las cuales contienen todo lo necesario para el aplicador del Derecho. Y concluye: la norma de conducta fundamental pudiera entonces ser descubierta ulteriormente, y sólo mediatamente, de esta norma de sanción (PERRON, Walter, "Die Stellung von Rechtfertigung und Entschuldigung im System der Strafbarkeitsvoraussetzungen", en: ESER, Albin; NISHIHARA, Haruo (Eds.), Rechtfertigung und Entschuldigung, Freiburg: MPI, 1995, p. 75).

${ }^{20}$ PERRON, "Die Stellung von Rechtfertigung", cit. nota n ${ }^{\circ} 19$, p. 76.
} 
MODOLELL, Juan Luis. "El tipo objetivo en los delitos de mera actividad".

\subsection{Función determinativa (motivadora) de la norma-desvalor de conducta-perspectiva $e x$ ante.}

En general para toda clase de delitos, sean de mera actividad o de resultado material, el carácter infractor de la conducta se vincula a lo que podría denominarse "función determinativa o motivadora de la norma penal" 21 . Al respecto, es gráfica la frase de Armin Kaufmann según la cual toda norma "desea" influir, su naturaleza es ser obedecida ${ }^{22}$. Ante la cuestión de si el imperativo normativo debe ser analizado en el ámbito del injusto o en la culpabilidad $^{23}$, considero que la función de determinación, como explicaré más adelante, se estudia primeramente en un plano objetivo (tipo objetivo), como estándar de conducta.

La referida función motivadora de la norma mediante la amenaza penal se fundamenta, a su vez, en el fin preventivo-general de la pena. El Derecho penal protege bienes jurídicos, intereses valiosos para la sociedad, función que en principio solo puede lograr tratando de influir en los destinatarios de la norma a través de dos maneras: a) amenazando con la aplicación de una sanción penal en caso de infringirse la norma (prevención general negativa); $y, b$ ) fomentando en los destinatarios de la norma el respeto (jurídico) al valor (más que a la propia norma) protegido por el tipo penal ${ }^{24}$. La norma del tipo de homicidio contiene la conminación a "no matar" y, a su vez, mediante esa amenaza envía el mensaje a sus destinatarios de que la vida es un interés valioso para la sociedad ${ }^{25}$. Esta última función (¿positiva?) de la prevención general sirve como límite de la intimidación, la cual de admitirse como único fin de la pena pudiera acarrear su desproporción y, en última instancia, la ausencia de una diferenciación punitiva entre los distintos delitos ${ }^{26}$ : si lo que persigue el Estado es intimidar a la población con la amenaza de la pena, sería entonces muy tentador para el legislador castigar igual todos los delitos, incluso sin forma alguna de limitación cualitativa. En cambio, si para la configuración de la amenaza penal se consideran también los bienes protegidos, los intereses que busca proteger el Derecho penal

\footnotetext{
${ }^{21}$ La califica como "función de la norma”, JAKOBS, Günther, Studien zum fahrlässigen Erfolgsdelikt, Berlin: W de G, 1972, pp. 7 y ss. Igualmente, MODOLELL, Bases fundamentales, cit. nota no 3, p. 299.

22 KAUFMANN, Armin, Teoría de las normas, BACIGALUPO, Enrique; GARZÓN, Ernesto (Trads.), Buenos Aires: Depalma, 1977, pp. 99 y ss. Según Baumann, Weber y Mitsch, "las normas cuya infracción hacen antijurídico el acto son...normas de determinación” (BAUMANN, Jürgen, WEBER, Ulrich, MITSCH, Wolfgang, Strafrecht. AT, Bielefeld: Gieseking, 2003, p. 304 -11-), por lo tanto lo antijurídico es la conducta, no el resultado (p. 304 -11-). En igual sentido, afirma Zielinski: "Ilícito es un concepto de correspondencia que es consecuencia de la estructura de la norma. Si la ley vincula una pena al ilícito, o no, es cuestión del merecimiento de pena de la infracción a la norma y de la necesidad concreta de pena de la acción contraria al deber. Ilícito es todo delito, es decir, toda acción final ejecutada en contra de una prohibición concretada en deber, o bien una acción final omitida en contra de un mandato concretado en deber" (ZIELINSKI, Diethart, Disvalor de acción y disvalor de resultado en el concepto de ilícito, SANCINETTI, Marcelo (Trad.), Buenos Aires: Hammurabi, 1990, p. 159). La concepción de la norma como un mandato se vincula a la llamada teoría de los imperativos (KRÜGER, Der Adressat, cit. nota ${ }^{\circ}$ 14, pp.77 y ss.). Crítico al respecto, LARENZ, Karl, Metodología de la ciencia del Derecho, RODRÍGUEZ MOLINERO, Marcelino (Trad.), Barcelona: Ariel, 1994, p. 248 y ss.; DEL MISMO, "Der Rechtssatz als Bestimmungssatz", en: BOCKELMANN, Paul; ENGISCH, Karl, Festschrift für Karl Engisch zum 70. Geburtstag, Frankfurt am Main: Vittorio Klostermann, 1969, pp. 150 y ss., especialmente la conclusión expresada en la p. 160.

${ }^{23}$ LUZÓN PEÑA, Curso, cit. nota no 8, pp. 64 y ss.

${ }^{24}$ Similar, MODOLELL, Bases fundamentales, cit. nota $\mathrm{n}^{\circ} 3$, pp. 300 y ss.

${ }^{25}$ MODOLELL, Bases fundamentales, cit. nota $\mathrm{n}^{\mathrm{o}} 3$, p. 301.

${ }^{26}$ MODOLELL, Bases fundamentales, cit. nota $n^{\circ} 3$, pp. 301 y ss.
} 
mediante la referida amenaza, entonces la pena para cada delito debe necesariamente ser diferente. Por mencionar un ejemplo, para la sociedad no significa lo mismo la vida de un ser humano que la propiedad privada, por lo tanto el homicidio y el hurto, tipos penales que protegen dichos intereses, no pueden ser castigados con la misma pena ${ }^{27}$.

Por otra parte, si bien la norma busca intimidar a un sujeto concreto, en un primer nivel de análisis del delito el mandato normativo se concibe como un estándar de conducta dirigido de forma indeterminada a la colectividad, sin atender a las particularidades del sujeto obligado $^{28}$. Así, el mandato de no matar a un hombre se dirige a todos los habitantes del ámbito de aplicación territorial de la ley penal, sin atender a si el sujeto concreto es motivable o no ${ }^{29}$. Dicho mandato supone la existencia de un destinatario ideal, determinable (en abstracto) por la norma. Esta forma de entender el momento normativo obedece a que los posibles destinatarios de la norma, por regla general, poseen capacidad de motivación, mientras que la incapacidad ocurre solo de forma excepcional. Además, la norma jurídica por su propia naturaleza uniformiza los hechos objeto de regulación (carácter general y abstracto de la norma) ${ }^{30}$.

Esta propiedad de generalidad y abstracción del mandato implica que un primer análisis de su infracción, y el correlativo desvalor de conducta, tengan carácter objetivo a nivel del tipo de injusto. "Objetivo" en este caso quiere decir "sin atender a la aceptación (obediencia) del mandato por parte del concreto destinatario", por lo tanto realizado mediante la comparación de la conducta analizada con la de un hombre medio-ideal, situado en la posición del autor. Dicho razonamiento es aplicable a cualquier delito, tanto a los delitos de resultado material como a los de mera actividad.

Si bien la indeterminación del mandato implica que a nivel del tipo objetivo, el análisis de la infracción de la norma no requierael conocimiento del hecho por el autor específico, ello en modo alguno quiere decir que posteriormente no deba tomarse en cuenta la concretización de ese mandato normativo en el sujeto. Esta última consideración se llevaría a cabo en el ámbito de la culpabilidad ${ }^{31}$. Lo que se quiere destacar es que a nivel del tipo penal se hace un primer análisis del alcance de la norma, in abstracto, de allí que la misma solo se entienda como estándar de conducta. El análisis del efecto de dicha norma en un sujeto concreto se realizará, posteriormente, en la culpabilidad, donde se precisará si dicho sujeto concreto fue capaz de motivarse por la norma atendiendo a las circunstancias

\footnotetext{
${ }^{27}$ En tal sentido afirma Mir Puig que la "función preventiva de las normas que imponen penas ha de estar limitada por los valores a cuya protección sirven” (MIR PUIG, $P G$, cit. nota no 7, p. 77 -41-).

${ }^{28}$ Así, BOCKELMANN, Paul; VOLK, Klaus, Strafrecht. AT, München: C.H. Beck, 1987, pp. 34 y ss.

29 “...antijuricidad significa para el Derecho penal más bien, también, la contradicción al enunciado jurídico de una norma de determinación o de conducta, la cual se refiere a un no deber hacer o un deber hacer, y cuyo destinatario es alguien sin consideración de la individual motivabilidad -de allí la posibilidad de un injusto sin culpabilidad-..." (SCHÖNKE, Adolf; SCHRÖDER, Horst; EISELE, Jörg, "Previo a los $\S \S 13$ y ss.", en: LOS MISMOS, Strafgesetzbuch. Kommentar, München: C.H. Beck, 2014, marginal 48). En igual sentido, ENGISCH, Karl, Auf der Suche nach der Gerechtigkeit, München: Piper, 1971, p. 31.

${ }^{30}$ Así, MODOLELL, Bases fundamentales, cit. nota ${ }^{\circ} 3$, pp. 305 y ss.

${ }^{31}$ Ver referencia a SCHÖNKE/SCHRÖDER/EISELE, "Previo a los $§ \S 13$ y ss.", cit. nota n 29.
} 
MODOLELL, Juan Luis. "El tipo objetivo en los delitos de mera actividad".

externas e internas presentes en él. Es en la culpabilidad donde se atienden a los factores particulares de motivación del sujeto ${ }^{32}$.

Para determinar el carácter desaprobado de la conducta es esencial valorarla desde un punto de vista ex-ante, es decir, con relación al momento en el cual un autor ideal debía captar y obedecer el mandato normativo. Como afirma Mir Puig, si se parte de una concepción preventiva del Derecho penal debe admitirse igualmente que la amenaza penal, la conminación penal, no puede limitarse a ser una respuesta frente al delito sino que ha de poder ser captada por el ciudadano (destinatario de la norma) en el momento de actuar, si es que la amenaza quiere incidir en su conducta ${ }^{33}$. Incluso, esta perspectiva ex ante constituye un criterio fundamental para la atribución de una lesión o un peligro al autor en los delitos de resultado material. Ellos pueden imputarse si ex ante eran predecibles para un hombre medio situado en la posición del autor, o si el mandato era captable en el momento de la realización de la conducta, igualmente para el hombre medio ${ }^{34}$. Sin embargo, el mismo razonamiento pudiera extenderse a los llamados tipos de mera actividad. En esta clase de delitos es fundamental la referencia a la perspectiva ex ante para atribuir al autor los distintos elementos que configuran el tipo penal, así como para afirmar si la conducta pudiera ser lesiva o peligrosa (en abstracto) de un bien jurídico. Más adelante explicaré como se manifiesta esta doble función de la perspectiva ex ante en los tipos de mera actividad.

\subsection{Función valorativa de la norma.}

De lo expresado anteriormente se desprende que la norma es un modo (medio) de comunicación utilizado por el Estado para dirigirse a los habitantes de su territorio ${ }^{35}$. Por lo tanto, ella expresa una voluntad (general) que tiene como fin lograr imponerse, influir en la conducta de los destinatarios como dije antes. Ahora bien, por ser un hecho comunicativo la norma no puede ser un cascarón vacío sino que, por el contrario, debe estar llena de significado, de sentido, tanto para el sujeto que la emite como para el receptor. El mandato debe "decirle algo" al destinatario, más allá de amenazarlo, más allá de la simple coacción. Al respecto, se puede hacer una analogía con la educación de los niños: si bien a un niño de corta edad sus padres le prohíben ciertas actividades, sin hacerle razonar mayormente el porqué de la prohibición, mientras crezca será indispensable explicarle el motivo de ella.

\footnotetext{
${ }^{32}$ MODOLELL, Bases fundamentales, cit. nota $\mathrm{n}^{\mathrm{o}} 3$, pp. 306 y ss.

${ }^{33}$ MIR PUIG, Santiago, "La perspectiva ex ante en Derecho penal", en: DEL MISMO, El Derecho penal en el Estado social y democrático de Derecho, Barcelona: Ariel, 1994, p. 95. Sostiene Mir Puig que la concepción preventiva de la pena es la que mejor puede cumplir el papel de regulación y evitación de conductas, fin que únicamente puede lograrse mediante una incidencia anterior a la conducta y que mire al futuro -perspectiva ex ante- (p. 96).

${ }^{34}$ Como también expresa Mir Puig, el pensamiento de la perspectiva ex ante se trasladó a la imputación objetiva, originalmente a la llamada teoría de la causación adecuada, según la cual la acción debe aparecer adecuada para producir el resultado a los ojos de un espectador medio que contemplara el hecho en el momento en que actuó el autor (ex ante), y con los conocimientos especiales que éste pudiera tener acerca de la situación (MIR PUIG, "La perspectiva ex ante", cit. nota $\mathrm{n}^{\circ} 33$, p. 98). Crítico al respecto, ZIELINSKI, Disvalor de acción, cit. nota $\mathrm{n}^{\circ} 22, \mathrm{p} .149$.

${ }^{35}$ En este sentido, BUSTOS, Juan (siguiendo a Callies), "Del estado actual de la teoría del injusto", en: DEL MISMO, Bases críticas de un nuevo Derecho penal, Santiago: Conosur, 1994, p.14; MAÑALICH, citando a Raz, "Norma e imputación", cit. nota n 13, p. 175.
} 
Cuando el niño crece, las prohibiciones irracionales y caprichosas por parte de los padres, hechas sin fundamento alguno, dejan de tener un efecto distinto al de generar rebeldía, resentimiento y, obviamente, desobediencia. Similar cuestión ocurre en la sociedad: el mandato normativo debe obedecer a un fin, a un valor que justifique la obediencia al mandato.

La norma debe tener significado para el destinatario medio, ofrecerle razones para su cumplimiento, distintas a la simple intimidación mediante la coacción. Es claro que la validez de la norma en modo alguno puede depender de su aceptación por parte del destinatario, sin embargo la norma debe partir de un destinatario ideal, de un sujeto medio que hipotéticamente la acepta en razón del valor y fin que persigue.

Partiendo del significado que debe tener el mandato, la norma no solo constituye un imperativo de conducta, un simple mandato de determinación dirigido a su destinatario, sino que cumple a su vez una función valorativa vinculada a un determinado interés considerado digno de protección ${ }^{36}$. En efecto, la norma jurídico-penal presupone un juicio de valor sobre un estado de cosas que se quiere mantener o evitar, de allí surge la prohibición de determinadas conductas porque se consideran peligrosas o lesivas de dicho estado de $\operatorname{cosas}^{37}$. Más aún, en el proceso de formación del enunciado legal contentivo de la norma jurídico-penal, el legislador primero realiza un juicio de valoración sobre determinados intereses y solo después crea el mandato que intentará motivar a su destinatario. Por lo tanto, la norma no es un simple mandato vacío de contenido sino un mandato con sentido. La norma, no expresa únicamente que deba realizarse una determinada conducta activa u omisiva, sino expresa también que el interés protegido por ella es valioso para la sociedad ${ }^{38}$.

\footnotetext{
${ }^{36}$ Sostiene la doble dimensión de la norma, por todos, JESCHECK, Hans-Heinrich, "Previo al $\S 13$ ", en: JESCHECK, Hans-Heinrich; RU $\beta$, Wolfgang; WILLMS, Günther (Eds.), Leipziger Kommentar, Berlin: De Gruyter, 2003, tomo I, p. 21 -43-. En cuanto al origen de esta doble función, dando preponderancia al aspecto objetivo, ver GUZMÁN DALBORA, José Luis, "Rudolph von Jhering y la concepción objetiva de la naturaleza de lo antijurídico“, en: VELÁSQUEZ et alii (Coords.), Derecho penal y crítica al poder punitivo del Estado. Libro homenaje a Nodier Agudelo, Bogotá: Ibañez-Universidad de Los Andes, 2013, tomo I, p. 226 -nota 56-.

37 Así, KRÜMPELMANN, Justus, Die Bagatelldelikte, Berlin: Duncker \& Humblot, 1964 -tesis doctoral-, p. 95; WOLTER, Jürgen, Objektive und personale Zurechnung von Verhalten, Gefahr und Verletzung in einem funktionalen Straftatsystem, Berlin: Duncker \& Humblot, 1981, pp. 26 y ss.). Por su parte, sostiene Münzberg que la valoración precede al mandato pero no constituye la norma jurídica (MÜNZBERG, Wolfgang, Verhalten und Erfolg als Grundlagen der Rechtswidrigkeit und Haftung, Frankfurt am Main: Vittorio Klostermann, 1966, p. 61). En la nota 120 afirma este autor que para la cuestión de si una conducta es o no antijurídica, es significativo sólo el concepto de deber jurídico como norma de determinación concretizada (p.61). No obstante, más adelante en la nota 122, sostiene este autor que la expresión protección de bienes jurídicos sería fin o meta de la norma de conducta, y ésta el medio para ello (p.61). Personalmente considero que la afirmación, repetida constantemente por la doctrina penal, de que la valoración precede al mandato pero que no forma parte de la norma, es inaceptable. De cierta forma, esa expresión implica que las valoraciones no tienen relevancia alguna en el Derecho penal. El mandato normativo no puede separase del fin que persigue, y por ende del valor que se trata de proteger. Un mandato vacío de contenido, como he dicho antes, sería pura coacción, pura violencia, cuestión incompatible con un Estado de Derecho.

${ }^{38}$ MODOLELL, Bases Fundamentales, cit. nota n ${ }^{\text {3 }}$, p. 209.
} 
MODOLELL, Juan Luis. "El tipo objetivo en los delitos de mera actividad".

En tal sentido, si se concibe la norma desde un punto de vista funcional, es decir, atendiendo al fin que ella deba cumplir, entonces su razón de ser (la decisión valorativa que origina su existencia) debe formar parte de ella: la valoración que la justifica debe ser un elemento fundamental de su estructura ${ }^{39}$. Esa valoración le atribuye sentido al mandato, constituye la razón de ser de su obediencia ${ }^{40}$.

Pero esta función de valoración que cumple la norma se vincula, como acabo de afirmar, con el interés que persigue proteger ${ }^{41}$. Esta aclaratoria viene al caso porque también pudiera sostenerse que la propia infracción de la norma implica una valoración. Afirmar que una conducta está o no prohibida implica un juicio de valor sobre su relación con el imperativo normativo ${ }^{42}$. Sin embargo, restringir la valoración al carácter desaprobado o no de la conducta sería vaciarla de contenido. Afirmar que la valoración ocurre cuando se determina el carácter prohibido o no de la conducta (si está prohibida=valoración negativa; si está permitida=valoración positiva) implicaría una explicación circular de la propia valoración. Se trataría de una simple valoración formal ${ }^{43}$. Considero que el juicio de valor se pregunta,

${ }^{39}$ En contra, implícitamente, Jakobs, para quien así como la legitimidad, por ejemplo, de las reglas del ajedrez o de las instrucciones de una maquina solo pueden ser valoradas, más allá de las consecuencias intrasistemáticas, desde un metasistema, así también es, sin duda alguna, la exactitud de la proposición de Derecho penal en el sistema (JAKOBS, Studien, cit. nota $\mathrm{n}^{\circ} 21$, pp. 4 y ss.).

${ }^{40}$ En este sentido, MALDONADO, Francisco, "Reflexiones sobre las técnicas de tipificación de los llamados "Delitos de peligro" en el moderno Derecho penal", REJ No 7 (2006), p. 28.

${ }^{41}$ Mañalich sostiene que la legitimidad de la norma de comportamiento deriva del bien jurídico que protege, aunque después da a entender que la imputación deriva de la justicia (MAÑALICH, "Norma e imputación", cit. nota $\mathrm{n}^{\mathrm{o}} 13$, pp. $174 \mathrm{y} \mathrm{ss)}$.

${ }^{42}$ En este sentido, LUZÓN PEÑA, Curso, cit. nota n 8, pp. 67 y 341; también LUZÓN PEÑA, "Voz Norma (penal)", cit. nota $\mathrm{n}^{\circ} 17$, p. 4445; igualmente, "Alcance y función", cit. nota 17, p. 56. Por su parte, se pregunta Engisch si el enunciado jurídico se agota en un imperativo: ¡También el ladrón del banco que le pide al cajero el dinero, con su revolver en frente, dirige a él un mandato! Junto al precepto jurídico pensamos siempre también en su obligatoriedad, su legitimidad, su validez, su juridicidad (ENGISCH, Auf der Suche, cit. nota $\mathrm{n}^{\circ} 29$, p. 31), y concluye: "En todo caso la apelación prima facie al bien fundado, factor de legitimación del Derecho no es contraria a la estructura imperativa de la norma jurídica" (p. 32). Deja claro Engisch que la norma al exigir determinada conducta también la valora; la orden aprueba y exige por lo tanto un hacer activo, y ese hacer es aprobado cuando la exigencia es satisfecha. La prohibición desaprueba una acción semejante y exige por lo tanto su omisión, así como también desaprueba una conducta contraria a la prohibición. Por lo tanto, las normas jurídicas no son únicamente normas de determinación sino también normas de valoración (p. 33). Sin embargo, Engisch no refiere la valoración al bien jurídico o interés protegido, ni a cualquier otro factor externo de legitimidad: "Incluimos en la función de valoración no demasiado, especialmente no el momento, antes rechazado, de la exactitud de la valoración según la medida de la idea jurídica. Entendemos la función de valoración, de cierta forma, en el sentido meramente lógico de aprobación o desaprobación, sin consideración a su legitimidad. Por lo tanto, no puede existir duda alguna de que el factor de mandato y el factor de valoración están entrelazados estrechamente uno con otro, y que el factor de valoración se tiene que aplicar para el examen de la exactitud" (p. 33). Reconoce Engisch que la función de valoración es también de especial significado para la aplicación jurídica, para la interpretación de la norma de Derecho, pues el límite del imperativo jurídico se ajusta según las valoraciones fundamentales (p. 34). Falso sería, sin embargo, considerar la norma jurídica exclusivamente como norma de valoración, pues la función de determinación debe colocarse antes de la función de valoración, con lo cual el Derecho puede llevar a cabo la respectiva configuración de la vida mediante la regulación de la conducta del obligado por el Derecho (p.34). Engisch es otro ejemplo de la aprehensión a considerar la valoración como indispensable en la norma jurídico-penal, aunque resalte su importancia.

${ }^{43}$ En tal sentido, distingue Zielinski entre la valoración primaria que tiene que ver con la lesión del bien jurídico, y la secundaria referida a la determinación de la conducta, aunque deja muy claro que el fin de la norma se reduce a la valoración secundaria. Según este autor, la norma de determinación tiene el fin exclusivo 


\section{Polít. crim. Vol. 11, No 22 (Diciembre 2016), Art. 2, pp. 368-390. \\ [http://www.politicacriminal.cl/Vol_11/n_22/Vol11N22A2.pdf]}

precisamente, porqué una conducta está prohibida o permitida. Dicha valoración fundamenta y legitima la prohibición. En un Estado de Derecho, característica que limita el poder punitivo, la función valorativa de la norma se vincula al interés protegido por el tipo penal $^{44}$. Sin referencia al interés protegido no puede concebirse una "valoración" legítima 45 .

El hecho de que la función valorativa de la norma se vincule al interés protegido por ella implica, a su vez, relacionarla con aquel momento en el cual la conducta delictiva pudiera afectar o poner en peligro dicho interés protegido por el tipo penal. En tal sentido, si la conducta no contiene igualmente una aptitud, ex ante, de lesión o peligro para el objeto del bien jurídico, debe concluirse entonces la ausencia de una conducta prohibida (como el caso de la tentativa absolutamente inidónea).

En suma, el tipo objetivo de cualquier delito se configura no solo con la simple ejecución material de los hechos descritos en la ley, sino fundamentalmente mediante el análisis de dicha ejecución conforme a las funciones que cumple la norma penal.

\section{El tipo objetivo en los delitos de mera actividad (conclusión).}

La tipicidad objetiva en los delitos de mera actividad consiste en determinar si la conducta realizada está abarcada por el ámbito de lo prohibido normativamente. Para ello debe precisarse si, desde un punto de vista ex ante, una persona media situada en la posición del autor hubiese contado con la existencia de los elementos típicos. Adicionalmente, en el caso de que se trate de un tipo penal de mera actividad y de peligro abstracto, debe analizarse, igualmente a partir de un punto de vista ex ante, si la conducta es estadísticamente peligrosa. Incluso, si se trata de un tipo de lesión de mera actividad, pudiera estudiarse la relevancia penal de dicha lesión ${ }^{46}$. Por lo tanto, para la adecuación típica (objetiva) se toman en cuenta dos aspectos: a) si desde un punto de vista ex ante un

de imponer lo que él denomina "juicio de valor secundario", es decir, prohibir el acto que debe no ser, o mandar el acto que debe ser, “...para servir con ello a la meta verdadera del ordenamiento jurídico-penal, pero no alcanzable directamente: realizar los juicios de valor primarios, evitar lesiones del objeto de bien jurídico que deben no ser, promover el mantenimiento del objeto del bien jurídico que debe ser. Norma (de determinación) y juicio de valor secundario tienen objetos idénticos: la acción contraria al valor o valiosa; si la norma es infringida, es realizado siempre también el objeto del juicio de valor secundario que subyace a la norma" (ZIELINSKI, Disvalor de acción, cit. nota $n^{\circ} 22$, pp. 133 y ss.). También esta opinión implica una concepción meramente formal de la valoración, en el sentido de circunscribirse a la desobediencia o no del mandato. En vez de entenderse así la valoración, resultaría más sincero prescindir de ella y restringir la norma al puro mandato, sin preguntarnos por las valoraciones "subyacentes". En todo caso, puntos de vista semejantes evidencian que algunos autores partidarios de la norma como exclusivo mandato imperativo, solapadamente, acepten que deba tener algún contenido "valioso" para su cumplimiento.

${ }^{44}$ Como bien expresa Bustos, el contenido de la norma no surge de ella misma "sino de valoraciones de algo en referencia", referencia cuyo eje es el bien jurídico (BUSTOS, "Del estado actual”, cit. nota n' 35, p. 16).

${ }^{45} \mathrm{Al}$ respecto, afirma Maldonado que la carencia de un interés relevante "deja las puertas abiertas a la arbitrariedad, permitiéndose la sanción de la mera desobediencia" (MALDONADO, "Reflexiones sobre las técnicas de tipificación", cit. nota n 40, p. 29). Destaca la función legimitadora del bien jurídico, PIÑA, Juan Ignacio, Derecho penal. Fundamentos de la responsabilidad, Santiago: Abeledo Perrot/Legal Publishing, 2010 , pp. 253 y ss.

${ }^{46}$ Como hace algún tiempo afirmó Nowakowski, también el delito de mera actividad deriva su injusto del perjuicio al objeto protegido (NOWAKOWSKI, Friedrich, "Zur Lehre von der Rechtswidrigkeit", ZStW Vol. 63 (1951), p. 326). En igual sentido, KÖHLER, Michael, Strafrecht. AT, Berlin: Springer, 1997, p. 128. 
MODOLELL, Juan Luis. "El tipo objetivo en los delitos de mera actividad".

observador objetivo contaría con la existencia de los diversos elementos (objetivos) exigidos por el tipo para su configuración (imputación al autor de las circunstancias típicas fundamentadoras de la conducta prohibida ${ }^{47}$ ); y b) si, desde un punto de vista ex ante, la conducta tiene la aptitud de ser peligrosa o lesiva para el objeto del bien jurídico ${ }^{48}$.

Valga el siguiente ejemplo para ilustrar el anterior esquema del tipo objetivo en los delitos de mera actividad: Después de la segunda guerra mundial el marido obtuvo una declaración judicial de muerte de su esposa desaparecida, lo cual permitió que contrajera un segundo matrimonio. Sin embargo, el marido contaba con la posibilidad de que su primera esposa aún viviera ya que había recibido alguna comunicación de ella y, efectivamente, se

\footnotetext{
${ }^{47}$ Este método de análisis se acepta concretamente para los delitos culposos. Así, afirma Andreas Hoyer: "En una norma que prohíbe conductas imprudentes debe ser alcanzable (obtenible) personalmente, por el destinatario de la norma, un determinado saber de la situación; para poder unir igualmente (asimismo) a esta situación la prohibición de la acción" (HOYER, Andreas, "Anh. Zu § 16 I/2", en: RUDOLPHI, HansJoachim; HORN, Eckhard; GÜNTHER, Hans-Ludwig; SAMSON, Erich (Eds.), Systematischer Kommentar zum Strafgesetzbuch, München: Luchterhand, $7^{\text {a }}$ edición -junio 2004-, tomo I, 39. Lfg, p. 13 -17-). Y agrega HOYER: "La norma de determinación (en el delito imprudente) debe vincular su mandato de prohibición a situaciones de hecho reconocibles para el destinatario de la norma" (p. 14 -19-). Lo descrito por Hoyer es aplicable igualmente a los delitos dolosos, sobre todo porque el saber referido tiene carácter objetivo: no se trata de lo que efectivamente el autor conocía al momento de la realización de la conducta, sino de lo que debía haber tenido en cuenta, tomando como referencia un observador objetivo situado en la misma posición del autor.

${ }^{48}$ En sentido similar, sostienen la ampliación de la imputación objetiva a los delitos de mera actividad, con base en el carácter peligroso de la conducta, TRIFFTERER, Otto, Österreichisches Strafrecht. AT, Wien-New York: Springer, 1994, p. 139 y ss. -81 y ss.- (sobre el detalle de la opinión de Triffterer, ver MODOLELL, "Consideraciones teóricas", cit. nota $\mathrm{n}^{\mathrm{o}}$ 7, pp. 238 y ss.). Ángel Torío López, siguiendo a Triffterer, se pronuncia también a favor de la ampliación de la imputación objetiva a los delitos de mera actividad (TORÍO LÓPEZ, Ángel, "Naturaleza y ámbito de la teoría de la imputación objetiva", ADPCP T. 39 (1986), p. 42), asociando la imputación de la acción a que esta sea peligrosa y jurídico-penalmente prohibida: "La reprochabilidad objetivo general es un juicio normativo que primariamente recae sobre la acción y sólo ulteriormente se refiere al resultado típico" (p. 45). Concretamente, con relación a la imputación objetiva, concluye Torío López lo siguiente: “...la imputación objetiva gravita prioritariamente sobre la contradicción entre la acción peligrosa y la norma jurídica concreta...Esta comprensión del concepto permite extender su operatividad a campos diversos de los delitos de resultado, donde despliega su función según la doctrina penal dominante. La imputación objetiva es una categoría que ha de ser tenida presente no sólo en los delitos materiales, o en los delitos de comisión por omisión, sino en todos los sectores del sistema penal. Establecido que la acción corresponde formalmente al tipo habrá que interrogar acerca de su reprochabilidad objetivogeneral. Esto ha de hacerse respecto a acciones subsumibles en tipos de simple actividad, en el tipo de la tentativa, en los distintos tipos de participación, etc..." (p. 47). Sin embargo, Torío López al igual que Triffterer no establece concretamente cómo se determina el carácter prohibido de la conducta, solo hace referencia a su carácter peligroso: “...La tipicidad no se agota en la concordancia lógico formal (subsunción) del hecho en el tipo. La acción descrita típicamente ha de ser generalmente peligrosa para un bien jurídico. La consideración lógico formal ha de ser integrada con la perspectiva material. Tal acción peligrosa, jurídicamente prohibida, se erige así en momento fundamental del sistema, del que sólo algunos fenómenos irregulares, como los llamados delitos de peligro abstracto, presentan una desviación o excepcionalidad...Esta posición, como decimos nada nueva, origina una amplificación del pensamiento de la imputación objetiva. No se limita ésta a los delitos materiales o de resultado. Por el contrario, se extiende también a los de simple actividad..." (TORÍO LÓPEZ, Ángel, "Fin de protección y ámbito de protección de la norma", Estudios penales y criminológicos $\mathrm{N}^{\circ} 10$ (1985-1986), p. 384 -cursivas mías-). Llama la atención que Torío López excluya de su construcción a los delitos de peligro abstracto.
} 
determinó tiempo después que el marido contrajera el segundo matrimonio, que aquella vivía $^{49}$. Se plantea así el problema sobre la existencia de un injusto objetivo de bigamia.

Suponiendo que el marido realmente ignorara que la primera esposa aún vivía, según lo explicado, el análisis en el tipo objetivo consistiría en determinar si desde un punto de vista ex ante existía la posibilidad de vigencia del primer matrimonio, para lo cual se tiene en cuenta si un observador objetivo debería contar con que la declaración judicial se basa en hechos verosímiles que hagan presumir razonablemente que la primera esposa ha fallecido, y la extinción del vínculo matrimonial. En tal sentido, por tratarse de una declaración judicial correctamente formulada, esta no debería ser puesta en duda o, mejor dicho, debe tenerse como cierta hasta prueba en contrario, sobre todo porque se basa en un dato cierto, concretamente en la desaparición de la primera mujer durante la guerra. En este supuesto, si se determina ex post que la mujer aún vive, como ocurre en el caso, la conducta del esposo de contraer un segundo matrimonio no estaría prohibida y, por ende, no sería punible. No se configuraría el tipo objetivo de bigamia.

Sin embargo, el caso del Tribunal Supremo alemán aporta un dato adicional digno de consideración: el marido cuenta con la posibilidad de que su primera esposa aún viva. Esta circunstancia sería, según la doctrina tradicional de la imputación objetiva, un "conocimiento especial del autor". En efecto, a nivel de la imputación objetiva del resultado material, un sector de la doctrina sostiene que la atribución del resultado varía según o no la existencia del conocimiento especial del autor. Así, el trillado ejemplo académico del sobrino, único heredero del tío rico, a quien convence para que realice un viaje en avión con la esperanza de que haya un accidente y él pueda heredar la fortuna. En caso de que el avión casualmente caiga, y muera el tío rico, el resultado no será imputable objetivamente al sobrino ya que su conducta no constituye un riesgo penalmente relevante. Se trata de un supuesto de riesgo socialmente admitido, pues volar en avión es una actividad de la cual no puede descartarse totalmente la posibilidad de un siniestro. No obstante, si el sobrino sabe que en el avión hay una bomba que con seguridad estallará a determinada hora, se imputará objetivamente el resultado. En el primer caso el autor dirige un curso causal a ciegas, sin saberlo, no así en el segundo supuesto ${ }^{50}$. Dicho conocimiento

\footnotetext{
${ }^{49}$ Basado en un caso del Tribunal Supremo alemán (ver BGH 4, 6).

${ }^{50}$ Con relación al juicio de imputación objetiva en el tipo doloso de resultado material, afirma Roxin la necesidad de dotar “....al observador del eventual saber especial del autor concreto...Así pues, si alguien aconseja a otro que dé un paseo, sabiendo que en el camino está al acecho un asesino, naturalmente habrá que afirmar que hay una creación de peligro, y el hecho será punible como asesinato...u...homicidio si se mata al paseante..." (ROXIN, DP, cit. nota $\mathrm{n}^{\circ}$ 1, p. 367 -46-; EL MISMO, AT, cit. nota $\mathrm{n}^{\circ}$ 1, p. 378 -56-). Igualmente, sostiene que para el juicio ex ante deben tenerse en cuenta las capacidades personales del autor, MALDONADO, "Reflexiones sobre las técnicas de tipificación“", cit. nota $n^{\circ}$ 40, p. 35. Lo anterior ha sido fuente de críticas al carácter objetivo de la imputación objetiva (Ver KAUFMANN, Armin, “¿ "Atribución objetiva" en el delito doloso?", ADPCP, T. 38 (1985), pp. 821 y ss.; CEREZO MIR, José, Curso de Derecho penal español, Madrid: Tecnos, 2005, tomo II -reimpresión sexta edición-, p. 106; STRUENSEE, Eberhard, "Acerca de la legitimación de la "imputación objetiva" como categoría complementaria del tipo objetivo", en: GUARIGLIA, Fabricio (Trad.), en: MAIER, Julio; BINDER, Alberto (Coords.), El Derecho penal hoy. Homenaje al prof. David Baigún, Buenos Aires: Editores del Puerto, 1995, pp. 263 y ss). También en contra del tratamiento de estos casos como problemas relativos al dolo del autor, ROXIN, "Reflexiones“", cit. nota $n^{\circ}$ 1, p. 132. Crítico de este último autor, ROJAS, Luis Emilio, "Lo subjetivo en el juicio de imputación objetiva: ¿aporía teórica?“, Revista de Derecho, Valdivia, vol. XXIII, Nº 1 (2010), p. 250.
} 
MODOLELL, Juan Luis. "El tipo objetivo en los delitos de mera actividad".

del autor solo agrega un dato más para concretar el juicio objetivo de imputación, que determinará el carácter prohibido o no de la conducta ${ }^{51}$. En el citado ejemplo del sobrino, la pregunta sería: ¿Es imputable el resultado de muerte a un hombre medio que convence a la víctima de subir a un avión, a sabiendas de que ese avión va a explotar? La respuesta obviamente debe ser afirmativa, en razón del dato adicional de concreción (conocimiento de la bomba). No por tomarse en cuenta un dato psicológico, deja el juicio de tener naturaleza objetiva. Correctamente expresa Cancio Meliá que la relevancia jurídico-penal de un hecho, la delimitación de "sucesivos $<<$ niveles de contexto $>>$ no puede hacerse conforme a un esquema simplista <<dentro de la cabeza-fuera de la cabeza $>$ >...En este sentido, <<objetivo>> significa concreción de la norma conforme a los patrones generales de un sujeto en un determinado papel social", y el valor "intersubjetivo" de la conducta puede variar en función de los datos conocidos por el sujeto actuante, y esa valoración es distinta de la que se realiza en el tipo subjetivo ${ }^{52}$.

Erróneamente pudiera pensarse que el asunto planteado constituye un tema relativo al dolo del autor, especialmente si se entiende el dolo como un concepto que debe ser imputado mediante criterios normativos ${ }^{53}$. En efecto, lo anterior no consiste en una forma de

\footnotetext{
${ }^{51}$ En efecto, la estandarización del mandato normativo se extiende a las habilidades especiales que pueda tener el autor (WOLTER, Jürgen, “Adäquanz- und Relevanztheorie. Zugleich ein Beitrag zur objektiven Erkennbarkeit beim Fahrlässigkeitsdelikt“", Goltdammer's Archiv für Strafrecht (1977), p. 269). Al respecto, afirma Rojas: "El contenido de la norma de conducta puede variar frente a la presencia de conocimiento especial, por lo que la determinación de su infracción también. Esto significa que este conocimiento es relevante frente a la norma de conducta $\mathrm{y}$, por tanto, puede ser valorado al momento de determinar la infracción de la norma” (ROJAS, "Lo subjetivo en el juicio de imputación“, cit. nota n 50, pp. 250 y ss.). Este autor sostiene la necesidad de valoración del conocimiento especial, en el ámbito de la imputación objetiva, conforme a una valoración de los intereses en conflicto -protección del bien jurídico versus ámbito de libertad- (pp. 251 y ss).

52 CANCIO MELIÁ, Manuel, Líneas básicas de la teoría de la imputación objetiva, Mendoza: Ediciones Jurídicas Cuyo, 2001, pp. 95 y ss.; también, DEL MISMO, “Algunas reflexiones sobre lo objetivo y lo subjetivo en la teoría de la imputación objetiva", en: BOLAÑOS, Imputación objetiva y dogmática penal, cit. nota $\mathrm{n}^{\circ} 7$, pp. 223 y ss. Más crítico se muestra este autor en: CANCIO MELIÁ, Manuel, “¿Crisis del lado subjetivo del hecho?”, en: LÓPEZ, Jacobo; ZUGALDÍA, José Miguel (Coords.), Dogmática y ley penal: libro homenaje a Enrique Bacigalupo, Madrid-Barcelona: Marcial Pons, 2004, pp. 63 y ss. Para Alex Van Weezel, la “...funcionalidad de las instituciones jurídicas respecto de la constitución social ha hecho que la teoría de la imputación objetiva aparezca a veces como una especie de objetivización de la imputación subjetiva. En realidad, se trata sólo de una impresión superficial, pues la imputación subjetiva es insustituible. De lo que se trata es de definir el segmento de los hechos que es relevante desde el punto de vista del juicio acerca de la motivación del autor: qué es lo que el autor, supuesta la motivación de respeto al derecho, tiene el deber de evitar, para luego determinar si podía personalmente evitarlo" (VAN WEEZEL, Alex, Error y mero desconocimiento en Derecho penal, Santiago: Legal Publishing, 2009, p. 43). Incluso, añade este autor que no debe darse prioridad a la imputación objetiva por sobre la subjetiva: "Sin la imputación subjetiva, el objeto de referencia de la imputación objetiva no se encuentra suficientemente concretado, pues recién la averiguación del horizonte de conocimientos personalmente posible para el autor proporciona el contexto en el que ha de enjuiciarse el suceso. Por eso es que no se trata de priorizar una parte de la imputación en desmedro de la otra, sino de un proceso unitario. Es en el marco de este proceso que la imputación subjetiva debe experimentar todavía una amplia normativización“ (p. 48).

${ }^{53}$ Así, por todos, RAGUÉS, Ramón, El dolo y su prueba en el proceso penal, Barcelona: J.M. Bosch, 1999, pp. 323 y ss.; 357 y ss.
} 
atribución del conocimiento, sino la manera de determinar el carácter prohibido (en general) de la conducta ejecutada ${ }^{54}$. Así, afirma Mir Puig:

“...la razón primera que fundamenta la prohibición de una determinada conducta -es decir, lo que mueve al legislador a querer prohibirla- es una característica externa de la misma, su peligrosidad ex ante para un bien jurídico. De ahí que, aunque sólo puedan prohibirse conductas voluntarias, y en la medida de su voluntariedad, lo que ha de decidir a prohibirlas no es su contenido psíquico negativo, sino su peligrosidad externa. Por otra parte, esta peligrosidad también debe decidirse objetivamente, en el sentido de que no depende del criterio del sujeto, sino del punto de vista de un observador objetivo situado ex ante. Aquí objetividad significa $<<$ intersubjetividad $>>$ "55.

Y agrega: "un Derecho que asuma como función la protección de bienes jurídicos ha de tratar de impedir aquellos hechos que ex ante parecen capaces de lesionarlos"56.

En el caso mencionado, al valorarse mediante una perspectiva ex ante si el matrimonio previo aún está vigente, precisamente el estado civil (bien jurídico) que se quiere proteger, se concluye si contraer el segundo matrimonio es una conducta prohibida o no: "Para decidir si un determinado comportamiento se halla o no prohibido por la ley penal, habrá que contemplar las características que manifiesta ex ante, cuando aún puede ser evitado. No cabe esperar a comprobar si, una vez realizado, el hecho resulta ser realmente como parecía, porque en un Derecho preventivo la decisión de prohibir o no prohibir el hecho debe adoptarse definitivamente antes de que el mismo se haya producido" ${ }^{57}$. En el ejemplo, la pregunta sería: ¿Se prohíbe la conducta de casarse por segunda vez, a sabiendas de que la esposa anterior aún vive?

Volviendo al delito de resultado material, de sostenerse que el conocimiento especial del autor (saber que en el avión hay una bomba) implica un problema relativo al dolo del autor, debería deducirse, entonces, la existencia previa del tipo objetivo únicamente con base en el vínculo causal ${ }^{58}$. Es decir, los partidarios de atribuir el conocimiento especial del autor al ámbito del dolo, deberían sostener, consecuentemente, que el tipo objetivo se conforma única y exclusivamente mediante la existencia de una relación de causalidad. Igual ocurriría en los tipos de mera actividad: el tipo objetivo en ellos se configuraría con la sola ejecución de la conducta. Sin embargo, conclusiones semejantes son incompatibles con una visión valorativa-normativa del Derecho penal. En efecto, modernamente nadie sostendría que un resultado causado se imputa al autor atendiendo únicamente a esa causación, sin resucitar el

\footnotetext{
54 Al respecto, ver opinión de Rojas trascrita en la nota $n^{\circ}$ 51. En el tipo objetivo debe determinarse, precisamente, el carácter prohibido de la conducta, la cual será objeto del dolo: objeto de este no es el tipo penal mismo, sino dicho tipo penal entendido como conducta prohibida presupuesta (FRISCH, Vorsatz, cit. nota $\mathrm{n}^{\circ} 9$, p. 352).

${ }^{55}$ MIR PUIG, Santiago, "Sobre lo objetivo y lo subjetivo en el injusto“, en: DEL MISMO, El Derecho penal en el Estado social y democrático de Derecho, Barcelona: Ariel, 1994, pp. 183 y ss.

${ }^{56}$ MIR PUIG, "Sobre lo objetivo", cit. nota $\mathrm{n}^{\circ}$ 55, p. 184.

${ }^{57}$ MIR PUIG, Santiago, "La perspectiva ex ante en Derecho penal”, en: DEL MISMO, cit. nota $n^{\circ} 55$, pp. 99 y ss.

${ }_{58}$ Así, ROJAS, citando a Frisch, "Lo subjetivo en el juicio de imputación”, cit. nota n 50, p. 246 -nota 86-.
} 
MODOLELL, Juan Luis. "El tipo objetivo en los delitos de mera actividad".

pensamiento "versarista". Igualmente, en el tipo de mera actividad no puede imputarse al autor ningún elemento objetivo del tipo únicamente por su "ejecución fáctica".

A todo evento, el intérprete debe distinguir los grados de ese conocimiento especial, necesarios para la imputación. Si, al margen de la declaración judicial, le consta realmente al marido que la primera esposa aún vive, o posee un conocimiento que con bastante probabilidad coincide con la realidad (existencia de la primera esposa), debe entonces afirmarse la realización del tipo en caso de que contraiga un segundo matrimonio. En cambio, si el esposo solo tiene una leve sospecha o una mera creencia de que su anterior cónyuge aún vive, circunstancia que ex ante no conduciría a un "observador objetivo" colocado en la posición del autor a contar racionalmente con ello, debería negarse el tipo objetivo incluso si se determina ex post la existencia de la mujer.

Al caso de bigamia relatado se le pudiera agregar una variante: supóngase que el autor actúa convencido de que su primera esposa todavía vive, o que el primer matrimonio aún es válido, circunstancias que, sin embargo, ex ante no son determinables racionalmente por un observador objetivo o cuya existencia es de una probabilidad bastante baja. En caso de que el esposo contraiga el segundo matrimonio bajo la creencia anterior, sin que el referido primer matrimonio exista realmente y sin que dicha existencia sea esperada racionalmente, no podría tampoco considerarse prohibida la conducta ya que la subsistencia del vínculo matrimonial previo sólo ocurre "en la mente del autor". Se trataría de un caso de tentativa inidónea no punible (según una antigua terminología, "tentativa inidónea absoluta"). En cambio, si el autor convencido de que el primer matrimonio aún es válido, contrae segundas nupcias, siendo factible su creencia desde un punto de vista ex ante, habría que afirmar la existencia de una tentativa inidónea punible ("tentativa inidónea relativa") aun cuando después de la celebración del segundo matrimonio se desvirtúe dicho convencimiento por la efectiva comprobación de la muerte de la primera mujer. En esta última variante se da la conducta prohibida, determinada desde un punto de vista ex ante (verosimilitud de la existencia de la primera esposa, según un observador objetivo situado en la posición del autor con los conocimientos concretos -especiales- de este), aunque ex post se desvirtúe tal circunstancia por la inexistencia del matrimonio anterior.

\section{Problemas concretos del tipo objetivo en delitos de mera actividad (análisis de casos).}

\subsection{Grupo de casos en los cuales debe imputarse al autor la un determinado elemento del tipo.}

Los siguientes ejemplos constituyen casos de atribución al autor de un elemento del tipo que simultáneamente resulta fundamental para afirmar el carácter prohibido de la conducta. Al respecto, es claro el caso de la bigamia citado anteriormente. Igualmente, vale el siguiente caso citado por Frisch: La muchacha aparenta, según su modo de comportarse y aspecto, más de 14 años. Ella consiente tener relaciones sexuales con un joven de 18 años. Sin embargo, se determina ex post que la edad de la muchacha era realmente de 13 años de edad $^{59}$.

\footnotetext{
${ }^{59}$ Delito contemplado en el § 178 del Código penal alemán. En Chile, art. 362 del Código Penal.
} 
Debe determinarse si un observador objetivo, situado en la misma posición del autor, hubiese podido contar con la existencia de la circunstancia relativa a la edad de la niña, por lo tanto valen las consideraciones hechas en el ejemplo de la bigamia referido antes. En este caso pudiera hacerse una precisión adicional: La existencia de una duda general, no individual, sobre la circunstancia señalada de la edad, determinada desde un punto de vista ex ante, conduciría a la prohibición de la conducta, incluso si se determina ex post que la niña realmente tiene 14 años de edad. Por lo tanto, si desde un punto de vista ex ante la niña pareciera tener menos de 14 años (también, por el modo de comportarse, desarrollo físico, etc.), o dicho de otra forma, existe una convicción general razonable (para el observador objetivo situado en la posición del autor) de que la niña tenga menos de esa edad, no podría entonces en este caso privilegiarse el ámbito de libertad de acción del autor en contra del bien jurídico. Existiría entonces la prohibición de realizar tal conducta: Si ex post se determina que la niña tiene efectivamente 14 años, pero ex ante (según un observador objetivo situado en el lugar del autor) parecía que tuviese menos, el hecho se imputaría a título de tentativa inidónea punible. El carácter inidóneo de la tentativa se fundamenta en la inexistencia durante todas las etapas del iter criminis, de la edad exigida por el tipo penal para la configuración de la conducta punible. No obstante, si ex ante (para cualquier observador objetivo situado en la posición del autor) existe la apariencia de dicha edad, ex ante existirá el peligro para el bien jurídico ya que la edad real solo se conoce ex post. La presencia ex ante de dicho peligro, descartado ex post, fundamenta el castigo a título de tentativa (inidónea), según la función de prevención general que debe cumplir la pena ${ }^{60}$. Obviamente, el iter criminis debe analizarse tomando en cuenta la percepción del autor y aquello que un hombre medio hubiese previsto, de estar en la posición del autor. Se trata de datos objetivos que califican el carácter peligroso, ex ante, de la conducta. En todo caso, en este último ejemplo en el cual la niña aparenta menos de 14 años, no se imputaría el hecho al autor si este supiera realmente su edad (conocimiento especial del autor que obra en su favor).

Como puede apreciarse, la edad en este delito constituye un elemento del tipo, el cual debe imputarse a la conducta del autor. Esto plantea la cuestión, como señalé antes, de si solo pueden atribuirse hechos causados, distintos a la conducta (resultado). En el ejemplo, el autor tiene relación con una menor de 14 años, con la particularidad de que no conocía dicha circunstancia. ¿Se le imputa ese hecho solo por haberlo realizado fácticamente? Si se tratara de un delito de resultado, sería claro que su sola manifestación causal no implicaría la imputación. En general, si el resultado no hubiese sido previsible ex ante, no se atribuiría a su causante. Ahora, ¿requieren un razonamiento distinto los tipos de mera actividad? ¿basta la sola ejecución de la conducta, para la realización del tipo objetivo? Desde mi punto de vista, la imputación al ejecutor material debe realizarse mediante criterios similares a los del tipo de acción de resultado material.

Como expresé antes, estos casos no constituyen supuestos de error sino problemas vinculados al ámbito objetivo del tipo, relacionados con la conducta prohibida. En razón de ello, los supuestos casos de error de tipo invencible, salvo que el yerro se deba a

\footnotetext{
${ }^{60}$ La fundamentación de la punibilidad de la tentativa inidónea en la peligrosidad ex ante de la conducta, se vincula con la función motivadora del Derecho penal (Ver MODOLELL, Juan Luis, Derecho penal. Teoría del delito, Caracas: UCAB, 2014, p. 165).
} 
MODOLELL, Juan Luis. "El tipo objetivo en los delitos de mera actividad".

condiciones particulares del autor (por ejemplo, ceguera, sordo-mudez, etc.), constituyen realmente supuestos a considerar en el ámbito del tipo objetivo. En última instancia, se trata de casos en los cuales desde un punto de vista ex ante ninguna persona (media) hubiese contado con la existencia de la circunstancia exigida por el tipo ${ }^{61}$.

Dentro de este grupo de casos también pudiera incluirse aquellos en los cuales deben determinarse las condiciones fácticas que obligan al autor a cumplir un deber (tipos de omisión propia): El sujeto se niega a pagar la pensión alimentaria de su supuesto hijo porque тиy probablemente él no es el padre biológico, ya que la madre tuvo relaciones sexuales con varios otros hombres durante los meses previos al comienzo del embarazo ${ }^{62}$.

El análisis del tipo objetivo en este caso, criterio aplicable a todo delito de omisión propia, se reduce a la siguiente fórmula: ex ante debe concurrir la posibilidad de existencia de las condiciones y presupuestos fácticos que fundamentan el deber de actuar. Por lo tanto, si ex ante (según un espectador objetivo situado en la posición del autor), hay dudas sobre esa posibilidad de existencia de las condiciones fácticas, la conducta no estaría prohibida. El mandato de realizar una conducta concreta solo es posible cumplirlo bajo determinadas condiciones objetivas exigidas por el tipo, condiciones cuya existencia sea previsible ex ante. En el ejemplo, un observador objetivo situado en la posición del autor y con sus conocimientos especiales pudiera pensar que el hijo, según las circunstancias del hecho, no es suyo. Una de estas circunstancias podría ser, como en el ejemplo de Frisch, que la madre durante el período previo a la concepción tuviera relaciones sexuales con otros hombres. Por lo tanto, el supuesto padre decide no pagar la manutención del hijo si antes no se determina quién es verdaderamente el padre del hijo. Las relaciones sexuales de la mujer con varios hombres durante el tiempo anterior de la concepción ponen en duda una condición fáctica objetiva del deber de alimentos: la relación de paternidad biológica. Entonces, si se determina ex post que el sujeto cuya paternidad es puesta en duda es realmente padre del niño, su conducta anterior de no pagar carecería de relevancia típica ya que ex ante existía la alta posibilidad de que el niño no fuere su hijo. Si el Derecho penal opera de manera excepcional no puede exigirse semejante conducta alguna al autor cuando las condiciones fácticas que fundamentan el deber de actuar son dudosas (para la generalidad) desde un punto de vista ex ante.

\subsection{Grupo de casos en los cuales la imputación objetiva en el delito de mera actividad se refiere a la cualidad de la conducta para afectar el bien jurídico protegido.}

Una persona divulga por internet material pornográfico donde aparecen imágenes de niños. Cuando la policía examina dicho material, se comprueba que las fotos constituyen una creación totalmente artificial, por lo tanto no se participaron niños en dichas fotos ${ }^{63}$.

En este caso, el análisis en el tipo objetivo no se refiere a la relación del autor con los elementos del tipo que fundamentan la prohibición, sino a la relación de la conducta del

\footnotetext{
${ }^{61}$ MODOLELL, Derecho penal, cit. nota $\mathrm{n}^{\circ} 60$, pp. 106 y ss.

${ }^{62}$ Ejemplo de FRISCH, Vorsatz, cit. nota $\mathrm{n}^{\circ}$ 9, p. 368. En Alemania, la falta de pago de la pensión alimentaria está contemplada como delito en el $\S 170$ b del Código penal alemán.

${ }^{63}$ Conducta que pudiera encuadrar en el artículo 374 bis CP chileno.
} 
autor con el interés protegido por la norma penal. Aquí debe analizarse si la foto, desde un punto de vista ex ante (según un observador objetivo) pareciera estar realizada con la participación de niños, supuesto en el cual se imputaría el hecho. Por el contrario, si desde la perspectiva ex ante se observa que las fotos son un burdo fotomontaje, no se podría configurar el peligro para el objeto del bien jurídico. En el ejemplo, el análisis mediante la perspectiva ex ante se refiere a la relación con el interés protegido: La divulgación del fotomontaje, según la referida apreciación ex ante, carece de aptitud para afectar la indemnidad sexual de los niños, y, más mediatamente, para el tráfico sexual de menores. Si el autor cree realmente que en la foto efectivamente intervienen niños, y en razón de ello divulga dicho material, se trataría de un caso de tentativa inidónea no punible.

Igualmente, en este grupo de casos pudieran incluirse aquellos donde la conducta de la propia víctima dispone del bien jurídico, y por lo tanto pierde relevancia jurídica cualquier posible afectación: A realiza una venta de garaje, abierta al público, en su casa. B aprovecha la situación, entra en el sitio y hurta uno de los bienes puesto en venta. En relación a este caso, se pregunta si existiría una violación de domicilio por la entrada en la vivienda, y por la permanencia en ella para realizar el hurto mencionado. Desde mi punto de vista, la conducta de A de realizar la venta abierta al público conduciría a pensar que, desde una perspectiva ex ante, se contaba con la posible permisión de entrar a dicha vivienda. Dicho de otra forma, un observador objetivo situado en la posición del autor hubiese dado por posible que la entrada a esa casa estaba permitida. Con relación a la conducta de la víctima, cabría el siguiente razonamiento: Al dejarse abierta la puerta de la morada para recibir potenciales compradores, se debe contar con que no solo personas con buenas intenciones sino también enemigos podrían entrar en ella. Por lo tanto, a dicha víctima se le debe imputar la realización de dicho riesgo, de allí que no se pueda afirmar el tipo objetivo de violación de domicilio.

\section{Conclusiones.}

La adecuación al tipo objetivo en los delitos de mera actividad no puede traducirse únicamente en la realización material del hecho. De ser así, los delitos de resultado material exigirían un análisis valorativo que sobraría en los de mera actividad, sin que se justifique este desigual tratamiento. Por lo tanto, considero que también para determinar la concurrencia de la parte objetiva de esta última clase de delitos es necesario hacer una valoración similar al de la imputación objetiva en los delitos de resultado material.

Para el referido análisis valorativo debe aplicarse el baremo de la perspectiva ex ante a los tipos de mera actividad. El mismo servirá para atribuir los elementos objetivos del tipo (sean descriptivos o normativos) al autor. Pero también, el uso del baremo podría extenderse a la posible afectación del bien jurídico protegido. Así, desde un punto de vista ex ante debe determinarse si la conducta es capaz de afectar valorativamente, no materialmente, el objeto del bien jurídico protegido (o constituir un peligro estadístico para el mismo). Algunas veces la primera forma de aplicación coincidirá con la segunda, concretamente cuando el tipo penal incorpore en su descripción un objeto que implique la materialización del bien jurídico, pero no necesariamente deben coincidir. 
MODOLELL, Juan Luis. "El tipo objetivo en los delitos de mera actividad".

En general, para toda clase de delitos, sean de mera actividad o de resultado material, el carácter infractor de la conducta se vincula a la función determinativa o motivadora de la norma penal. A su vez, esa función motivadora de la norma se fundamenta en el fin preventivo-general de la pena.

La función motivadora de la norma servirá para determinar la concurrencia del tipo objetivo. Se parte de un mandato que opera como estándar de conducta dirigido de forma indeterminada a la colectividad sin atender a las particularidades del sujeto obligado. Para afirmar el carácter desaprobado de la conducta es esencial valorarla desde un punto de vista ex-ante, con relación al momento en el cual el autor debía captar y obedecer el mandato normativo.

Sin embargo, la norma no constituye solo un imperativo de conducta, un simple mandato de determinación dirigido a un destinatario ideal, sino también cumple una función valorativa sobre un determinado hecho. La norma jurídico-penal implica igualmente un juicio de valor sobre un estado de cosas que se quiere mantener o evitar. Esta función de valoración se vincula al interés que persigue proteger.

El hecho de que la función valorativa de la norma se refiera al interés protegido por ella, implica, a su vez, relacionarla con el posible momento en el cual la conducta delictiva pudiera afectarlo o ponerlo en peligro, en sentido valorativo del término: lesión o peligro de un bien jurídico.

El análisis de la conducta en su relación con la norma (análisis sobre el carácter desaprobado de la conducta) se realiza desde un punto de vista ex ante. Al respecto, en el tipo de mera actividad deben analizarse dos aspectos: a) Si desde un punto de vista ex ante un observador objetivo contaría con la existencia de las diversos elementos exigidos por el tipo para su configuración; b) Si un observador objetivo contaría, ex ante, con la posibilidad de que su conducta es peligrosa o lesiva para el objeto del bien jurídico protegido. 
Polít. crim. Vol. 11, No 22 (Diciembre 2016), Art. 2, pp. 368-390.

[http://www.politicacriminal.cl/Vol_11/n_22/Vol11N22A2.pdf]

\section{BIBLIOGRAFÍA}

BAUMANN, Jürgen, WEBER, Ulrich, MITSCH, Wolfgang, Strafrecht. AT, Bielefeld: Gieseking, 2003.

BINDING, Karl, Die Normen und ihre Übertretung, Leipzig: Engelmann, 1872, tomo 2, 1.

BOCKELMANN, Paul; VOLK, Klaus, Strafrecht. AT, München: C.H. Beck, 1987.

BUSTOS RAMÍREZ, Juan, "Del estado actual de la teoría del injusto" en: DEL MISMO, Bases críticas de un nuevo Derecho penal, Santiago: Conosur, 1994, pp. 5 y ss.

CANCIO MELIÁ, Manuel, Líneas básicas de la teoría de la imputación objetiva, Mendoza: Ediciones Jurídicas Cuyo, 2001.

" ¿Crisis del lado subjetivo del hecho?” en: LÓPEZ, Jacobo; ZUGALDÍA, José Miguel (Coords.), Dogmática y ley penal: libro homenaje a Enrique Bacigalupo, Madrid-Barcelona: Marcial Pons, 2004, pp. 63 y ss.

, "Algunas reflexiones sobre lo objetivo y lo subjetivo en la teoría de la imputación objetiva”, en: BOLAÑOS, Mireya (Coord.), Imputación objetiva y dogmática penal, Mérida: Universidad de Los Andes, 2005, pp. 205 y ss.

CEREZO MIR, José, Curso de Derecho penal español, Madrid: Tecnos, 2005 -reimpresión sexta edición-, tomo II.

ENGISCH, Karl, Auf der Suche nach der Gerechtigkeit, München: Piper, 1971.

FRISCH, Wolfgang, Vorsazt und Risiko, Köln-Berlin-Bonn-München: Carl Heymanns, 1983.

GRAUL, Eva, Abstrakte Gefährdungsdelikte und Präsumtionen im Strafrecht, Berlin: Duncker \& Humblot, 1991.

GUZMÁN DALBORA, José Luis, "Rudolph von Jhering y la concepción objetiva de la naturaleza de lo antijurídico", en VELÁSQUEZ et alii (Coords.), Derecho penal y crítica al poder punitivo del Estado. Libro homenaje a Nodier Agudelo, Bogotá: Ibañez-Universidad de Los Andes, 2013, tomo I.

HOYER, Andreas, “Anh. Zu § 16 I/2”, en: RUDOLPHI, Hans-Joachim; HORN, Eckhard; GÜNTHER, Hans-Ludwig; SAMSON, Erich (Eds.), Systematischer Kommentar zum Strafgesetzbuch, München: Luchterhand, 7 a edición -junio 2004-, tomo I, 39. Lfg.

JAKOBS, Günther, Studien zum fahrlässigen Erfolgsdelikt, Berlin: W de G, 1972. , Strafrecht. AT, Berlin-New York: W de G, 1993.

, Derecho Penal. PG, CUELLO CONTRERAS, Joaquín; SERRANO GONZÁLEZ DE MURILLO, José (Trads.), Madrid: Marcial Pons, 1995.

JESCHECK, Hans-Heinrich, "Previo al § 13", en: JESCHECK, Hans-Heinrich; RU $\beta$, Wolfgang; WILLMS, Günther (Eds.), Leipziger Kommentar, Berlin: De Gruyter, 2003, tomo I.

KAUFMANN, Armin, Teoría de las normas, BACIGALUPO, Enrique; GARZÓN, Ernesto (Trads.), Buenos Aires: Depalma, 1977.

, “¿ "Atribución objetiva" en el delito doloso?”, ADPCP, T. 38 (1985), pp. 821 y SS.

KÖHLER, Michael, Strafrecht. AT, Berlin: Springer, 1997.

KRÜGER, Uwe, Der Adressat des Rechtsgesetzes, Berlin: Duncker \& Humblot, 1969.

KRÜMPELMANN, Justus, Die Bagatelldelikte, Berlin: Duncker \& Humblot, 1964 -tesis doctoral-. 
MODOLELL, Juan Luis. "El tipo objetivo en los delitos de mera actividad".

, "Schutzzweck und Schutzreflex der Sorgfaltspflicht", en: KAUFMANN, Arthur (Ed.), Festschrift für Paul Bockelmann, München: C.H. Beck, 1979, pp. 444 y ss.

LAMPE, Ernst-Joachim, "Unrecht und Schuld, Sühne und Reue" en: ARZT, Günther; BAUMANN, Jürgen, Festschrift für Jürgen Baumann, Bielefeld: Gieseking, 1992, pp. 24 y ss.

LARENZ, Karl, "Der Rechtssatz als Bestimmungssatz", en: BOCKELMANN, Paul; ENGISCH, Karl, Festschrift für Karl Engisch zum 70. Geburtstag, Frankfurt am Main: Vittorio Klostermann, 1969, pp. 150 y ss.

, Metodología de la ciencia del Derecho, RODRÍGUEZ MOLINERO, Marcelino

(Trad.), Barcelona: Ariel, 1994.

LUZÓN PEÑA, Diego-Manuel, “Alcance y función del Derecho penal” en: DEL MISMO, Estudios Penales, Barcelona: PPU, 1991, pp. 15 y ss.

"Voz <<Norma (penal) de determinación y de valoración", en: VV.AA., Enciclopedia Jurídica Básica, Madrid: Civitas, 1995, vol. III, p. 4445.

, Curso de Derecho penal. PG, Madrid: Universitas, 1996.

MALDONADO, Francisco, "Reflexiones sobre las técnicas de tipificación de los llamados "Delitos de peligro" en el moderno Derecho penal", REJ No 7 (2006), pp. 23 y ss.

MAÑALICH, Juan Pablo, "Norma e imputación como categorías del hecho punible", REJ $\mathrm{N}^{\mathrm{o}} 12$ (2010), pp. 169 y ss.

MAURACH, Reinhart; ZIPF, Heinza, Strafrecht. AT, Heidelberg: C.F. Müller, 1992, tomo I.

MAYER, Max-Ernst, Normas jurídicas y normas de cultura, GUZMÁN DALBORA, José Luis (Trad.), Buenos Aires: Hammurabi, 2000.

MIR PUIG, Santiago, "La perspectiva ex ante en Derecho penal" en: DEL MISMO, El Derecho penal en el Estado social y democrático de Derecho, Barcelona: Ariel, 1994. , "Sobre lo objetivo y lo subjetivo en el injusto" en: DEL MISMO, El Derecho penal en el Estado social y democrático de Derecho, Barcelona: Ariel, 1994. , Derecho Penal. PG, Barcelona: Reppertor, 2015.

MODOLELL, Juan Luis, Bases fundamentales de la teoría de la imputación objetiva, Caracas: Livrosca, 2001.

"Consideraciones teóricas sobre la posibilidad de extensión de la imputación objetiva a los delitos de mera actividad", en: BOLAÑOS, Mireya (Comp.), Imputación objetiva y dogmática penal, Mérida: Universidad de Los Andes, 2005, pp. 236 y ss.

, Derecho penal. Teoría del delito, Caracas: UCAB, 2014.

MÜNZBERG, Wolfgang, Verhalten und Erfolg als Grundlagen der Rechtswidrigkeit und Haftung, Frankfurt am Main: Vittorio Klostermann, 1966.

NOWAKOWSKI, Friedrich, "Zur Lehre von der Rechtswidrigkeit”, ZStW Vol. 63 (1951), p. 326.

PERRON, Walter, "Die Stellung von Rechtfertigung und Entschuldigung im System der Strafbarkeitsvoraussetzungen" en: ESER, Albin; NISHIHARA, Haruo (Eds.), Rechtfertigung und Entschuldigung, Freiburg: MPI, 1995, p. 75.

PIÑA, Juan Ignacio, Derecho penal. Fundamentos de la responsabilidad, Santiago: Abeledo Perrot/Legal Publishing, 2010.

RAGUÉS, Ramón, El dolo y su prueba en el proceso penal, Barcelona: J.M. Bosch, 1999.

ROJAS, Luis Emilio, "Lo subjetivo en el juicio de imputación objetiva: ¿aporía teórica?" Revista de Derecho, Valdivia, vol. XXIII, No 1 (2010), p. 250. 
Polít. crim. Vol. 11, No 22 (Diciembre 2016), Art. 2, pp. 368-390.

[http://www.politicacriminal.cl/Vol_11/n_22/Vol11N22A2.pdf]

ROXIN, Claus, "Reflexiones sobre la problemática de la imputación en el Derecho penal" en: DEL MISMO, Problemas básicos del Derecho penal, Madrid: Editorial Reus, 1991.

, Derecho Penal. PG, LUZÓN PEÑA, Diego-Manuel; DÍAZ Y GARCÍA CONLLEDO, Miguel; DE VICENTE REMESAL, Javier (Trads.), Madrid: Civitas, 1997.

, Strafrecht. AT, München: C.H. Beck, 2006, vol. I.

SCHÖNKE, Adolf; SCHRÖDER, Horst; EISELE, Jörg, "Previo a los $\S \S 13$ y ss.", en: LOS MISMOS, Strafgesetzbuch. Kommentar, München: C.H. Beck, 2014.

STRUENSEE, Eberhard, "Acerca de la legitimación de la "imputación objetiva" como categoría complementaria del tipo objetivo“, en: GUARIGLIA, Fabricio (Trad.), en: MAIER, Julio; BINDER, Alberto (Coords.), El Derecho penal hoy. Homenaje al prof. David Baigún, Buenos Aires: Editores del Puerto, 1995, pp. 263 y ss.

TORÍO LÓPEZ, Ángel, "Naturaleza y ámbito de la teoría de la imputación objetiva", ADPCP T. 39 (1986), pp. 33 y ss.

"Fin de protección y ámbito de protección de la norma", Estudios penales y criminológicos $\mathrm{N}^{\circ} 10$ (1985-1986), pp. 381 y ss.

TRIFFTERER, Otto, Österreichisches Strafrecht. AT, Wien-New York: Springer, 1994.

WOLTER, Jürgen, "Adäquanz- und Relevanztheorie. Zugleich ein Beitrag zur objektiven Erkennbarkeit beim Fahrlässigkeitsdelikt”, Goltdammer's Archiv für Strafrecht (1977), pp. 256 y ss.

Objektive und personale Zurechnung von Verhalten, Gefahr und Verletzung in einem funktionalen Straftatsystem, Berlin: Duncker \& Humblot, 1981.

ZIELINSKI, Diethart, Disvalor de acción y disvalor de resultado en el concepto de ilícito, SANCINETTI, Marcelo (Trad.), Buenos Aires: Hammurabi, 1990. 